\title{
Investigating the Effect of Monetary Shock on the Activity Level of Industrial Units in Iran Using the FAVAR Model
}

\author{
Zahra Ranjbar and Seyed Mohammad Kazem Etemad*
}

Department of Industrial Engineering, Faculty of Engineering, Zand Institute of Higher Education, Shiraz, Iran

\section{*Corresponding Author: \\ \etemad2007@gmail.com}

Received: 15 February, 2021

Accepted: 30 March, 2021

Published: 30 April, 2021

\begin{abstract}
Today, economic development is not possible without paying attention to the industrial sector. Industry is one of the infrastructural sectors of the economy that plays an important role in determining the cycles of prosperity and recession Also, the monetary policy is one of the important macroeconomic policies of the country which due to the importance of the industrial sector in Iran's economy and the need to adopt appropriate monetary policies, this study tries to investigate the effect of monetary shocks including liquidity shock and monetary base shock on the level of activity of industrial units in the country. For this purpose, statistical data from 1978 to 2016 and a Factor augmented vector auto regressive (FAVAR) model have been used to determine the relationships and effects of shocks and their analysis. The research findings indicate that a positive monetary shock (increase in money supply) has expansionary effects on the count growth of Industries and the investment of these industries in Iran's economy. Also, the count of industries and their investment According to liquidity shocks have a faster and more stable response than monetary base shocks.
\end{abstract}

Keywords: Monetary Policy, Industrial, Liquidity, Factor Augmented Vector Auto Regressive (FAVAR)

\section{Introduction}

Most economists believe that monetary policy has real effects in the short term; but in the long run it is neutral. Due to the monetary policy channels and the differences between the economic sectors in this regard, it is expected that the economic sectors will show unequal reactions to a monetary policy shock. In recent decades, the impact of monetary policy and shocks on the real economy has been considered as an important question .But what is being debated today is the impact of monetary policy and shocks on aggregate demand and real variables. In general, monetary policy is the policy of the central bank, which is used to control and guide money, maintain and protect its value, and provide simple and secure conditions for the continuous economic growth of society. Usually, the general level of prices, employment rate, real national production, and balance of payments are the most important macroeconomic variables, which their increase, decrease, or stabilizing is the ultimate goal of monetary policy.

One of the requirements of the implementing a correct and successful policy is being aware of its effects and consequences. When the central bank implements a contractionary monetary policy to curb inflation, it must be aware of the extent and speed of the general level of price reaction to this contractionary policy. Also, given the impact of money on production and employment in according to short-term, it is important to know the reaction of the production to this contractionary policy; because the result of this policy, may put the economy in a state of stagnation which its economic and social costs will not be less than inflation. In fact, the policymaker needs to know which variables at what time and to what extent will react to the policy. Therefore, the more information about the effects of monetary policy and the ways it affects 
economic variables are available, the more efficient monetary policies will be implemented. Accordingly, the purpose of this paper is to identify the behavior of the main industry's variables in response to a monetary shock and the main question of this research is how to evaluate the reactions activity levels of the country's industries, including the count, investment and their employment relative to monetary shock.

\section{Subject Literature}

In the recent decade's study of the effects of monetary policy (monetary shock) on macroeconomic variables has been one of the main topics of monetary economics. After Sims study [1], VAR method is used Extensively in studies of the effects of economic shocks, especially monetary shocks in different countries. Carare and Popescu (2011) in Hungary, Hsing [2] in Argentina, Borys and Horvath (2008) in the Czech Republic, Anzuini and levy (2007). In the new members of the European Union, Miyao (2006) in Japan, Brischetto and Voss (1999) in Australia are some of the studies using the VAR method and its various forms have to examine the effects of monetary policy shocks .For example, Carare and Popescu (2011) used a Bayesian approach of VAR and Borys and Horvath (2008) used Structurally VAR in estimates of instantaneous reaction functions. In addition to the estimate approach of VAR model Determining model variables is also very important. In all of these studies, the interest rate variable is considered as a monetary policy indicator.

Also, Bernanke et al. [3], Tomola et al. (2012) and Eze and Ogiji (2013) using dynamic factor patterns in vector auto regressive models, introduced the Factor augmented vector auto regressive method. They measured the effects of monetary policy on macroeconomics using these models.

Clements's study (2016) predicted the economic situation and the reasons of economic instability in the United States.He used vector auto regressive and Factor augmented vector auto regressive model, to test their data and found that real data has more predictive power than nominal data. He also showed that predicting variables based on Factor augmented vector auto regressive model compared to vector auto regressive model has more robust results and the price riddles is disappeared using FAVAR model.

Metiu (2016) based Factor augmented vector auto regressive model, examined the capital market reaction when bank's lending standards change in the United States.He used foreign financing as a monetary measure.He found that after the unexpected change in capital market financing standards, the index would fall by 1.36 percent after two years, while this change would be negligible if the standards were changed over time.

Alikhani et al (1389), Hassanshahi et al (2011) and Khezri et al (2015) through VAR and FAVAR model, study the effects of monetary shocks on agriculture and industry. The results indicate that the monetary policy has short-lived impact on industrial and agricultural exports which is positive and significant effect.

Marzban et al. [4] evaluated the efficiency of monetary policy in Iran's economy. On this basis this study used Factor augmented vector auto regressive and maximize expectations algorithm and 120 economic variables during 1979 - 2013 assess money policy efficiency in Iran. The results show that interest rate shock delay effect on money market so that in case of facing Hit Has with deviation criterion, Money market interest rate shock would react to this shock whit three months' delay. This Issue Has the same response to work and the product market.

\section{Methodology}

\section{Theoretical foundations}

The interaction between monetary variables and real economic variables is critical to guide monetary policy. To implement a successful monetary policy, monetary authorities need to have an accurate assessment of the timing and extent of this policy's impact on various sectors of the economy. Therefore, understanding monetary policy effects on macroeconomic variables will be important for monetary authorities to achieve policy goals such as price stability and economic growth. However, most economists agree that monetary policy can have a significant impact on the real economy at least in the short term. With this description, we see that monetary policy has suitable place in economic theoretical discussions, so it becomes a way of thinking and a group has been of researchers and economists see the issue from this perspective views.

There are many different regarding the impact of monetary policy on the real sector of the economy. Although the hypothesis of the duality of the classics before the great crisis of 1929 make no interaction between real and nominal variables in short and long terms. But today most economists believe that changes in prices and the amount of money or in general the impulse nouns, behavior of real variables such as production, consumption and employment will be affected in the short term. Most economists do not accept that money is neutral at least in short term. In fact, many researchers attribute a large share of trade fluctuations to monetary shocks. Their view is that monetary expansion will stimulate real economic activity, and on the contrary, a contractionary 
monetary policy will lead to a stagnation. Theoretically, believe that the volume of money does not affect real variables, even in the short term, and therefore the mechanism of transferring monetary policy is limited and has no study value. While other schools of economics such as Keynesians, Polynesians, neoKeynesians, neoclassicists, etc., believe in the shortterm effects of monetary shocks of course, the source of which can vary. In addition to disagreements about the source and the effectiveness of monetary policy, there are other cases such as uncertainties about effectiveness, channels of influence, the time needs to onset the effect, durability of effect and the peak time of effect is also the conflict between economists. The results of broad literature review of monetary policies showed, classics do not believe in the effectiveness of monetary policy and its implementation will only follow price changes. In this way, it will not affect the distribution of income and welfare. In contrast, Keynesians believe that for certain prices, increasing the nominal volume of money increases real money supply; as a result, the rate of balance interest declined and follow, that investment and production will increase, too. In this way, employment and income are affected, and this will affect welfare. Monetarist's position was that among the existing policies, monetary policy could change the overall demand and thus affect production and prices. New classics, with rational expectations and wage flexibility, stated that in the case of predictable monetary policy, these policies are neutral .But if unpredictable, monetary policy can affect the production and well-being of society. The view of real business circles is that monetary policy is completely passive, and what changes production is a change in technology and productivity. Finally, NewKeynesian believed in a lack of full flexibility in wage and prices in the short term, and argue that monetary policy can affect real economy variables, including manufacturing, at least in the short-term.

In addition to the controversy over the effects of money on real variables, the issue of asymmetry of monetary shocks addresses the fundamental question of whether the positive and negative shocks of money supply have similar effects on economic activity. Since the 1930s, some economists such as Keynes and Pigou have argued that monetary policy can have asymmetric effects on production during periods of recession and economic prosperity .In fact, if part of the supply curve can be considered vertical, monetary policy will have less impact on production over prosperity time. They emphasize that the experimental literature of the new classics does not distinguish between the positive and negative monetary shocks correspondent to the effects of monetary shocks. If this argument is correct and such a distinction is important, then the traditional some economics schools, such as business circles, approach to testing the neutrality of unexpected monetary changes is not valid and ignores economic conditions, in analyzing the effects of monetary shocks both during the recession and the boom.

\section{Method}

VAR models on various variables and different sector of economic to analysis of the effects of monetary shocks in the literature of money transfer mechanisms. But one of the main features of these models is that we cannot use a large number of variables. The reason of this limitation in using variables in traditional VAR models is that, as the number of variables used in this pattern increases, the degree of freedom decreases rapidly, because in each equation, the dependent variable will estimate on its own interruptions and other variables interruptions. Therefore, it is not possible to using a large number of variables in this model. Limitations of variables in the traditional VAR model cause problems in the analysis of monetary shock on economy. Another problem is inefficient use of information in the economic data and the selective use of a limited number of variables which leads to not comprehensive and complete evaluation of monetary shocks. Another problem is that variables are selected based on researchers' tastes and choices. With consideration of these problems, recently, much attention has been paid to the structure and content of models include extensive economic information. This process is done through the evolution and development of traditional VAR models and with the help of one or more factors. The first leading studies in this field were those of Bernanke and Boivin [5], and Bernanke et al. [6]. The achievement of these two studies is completed traditional VAR model by adding several factors. Following this study, other articles have been published that have conducted similar studies, each of which has made special innovations in this area, including Bernanke et al. [3], Dave et al. (2009), Stoke and Watson (2005) and Boivin et al. [7].

In this study, statistical data related to the period 1978 to 2016 have been extracted from the data of the Central Bank of the Islamic Republic of Iran. Since The requirement for factors estimation using the Factor augmented vector auto regressive model is that the variables are static, tests such as the Augmented dickeyfuller (ADF) unit root test and Philips-Perron (PP) test were performed to evaluate the static of variables, in which case the data have the necessary conditions for the final estimation of the model.

\section{Pattern structure}

Suppose that $Y_{t}$ with dimensions $M \times 1$ And $X_{t}$ with dimensions $\mathrm{N} \times 1$ are two vectors of economic Page | 10 
variables that we intend to examine. in addition, $\mathrm{t}=$ Actually $\mathrm{Y}_{\mathrm{t}}$ are exogenous variable which are controlled by economic policymakers and $X_{t}$ is a large collection of economic data related to other economic variables, assume that there are some basic factors or forces beyond observation that affects the dynamics of $X_{t}$ over time. If these factors are represented by the vector $F_{t}$ which has dimensions $K \times 1$, then the relationship between $\mathrm{F}_{\mathrm{t}}$ And $\mathrm{X}_{\mathrm{t}}$ is modeled as follows:

$X_{t}=\Lambda F_{t}+e_{t}$

In where $e_{t}$ is the error vector with zero average, the components of which may also have a weak correlation with each other. Vector $\mathrm{X}_{\mathrm{t}}$ is a vector of $\mathrm{N} \times 1$ and $\sum \mathrm{iNi}=\mathrm{N}$. In this case, it is assumed that each of the vectors $X_{t}$ are explained only by some elements of the vector $\mathrm{F}_{\mathrm{t}}$ where $\mathrm{F}_{\mathrm{t}}$ is a vector $\mathrm{K} \times 1$ and $\sum \mathrm{iKi}=\mathrm{K}$. It must also $\mathrm{Ki}<\mathrm{Ni}$. In addition, it is assumed that each vector of $X_{t}$ is represented by Only one $F_{t}$ vector. As a result, equation (1) will be as follows:

$\left[\begin{array}{c}X_{t}^{1} \\ X_{t}^{2} \\ \cdots \\ X_{t}^{I}\end{array}\right]=\left[\begin{array}{cccc}\Lambda_{1}^{f} & 0 & \cdots & 0 \\ 0 & \Lambda_{2}^{f} & \cdots & 0 \\ \cdots & \cdots & \cdots & \cdots \\ 0 & 0 & \cdots & \Lambda_{I}^{f}\end{array}\right] \times\left[\begin{array}{c}F_{t}^{1} \\ F_{t}^{2} \\ \cdots \\ F_{t}^{I}\end{array}\right]+\left[\begin{array}{c}e_{t}^{1} \\ e_{t}^{2} \\ \cdots \\ e_{t}^{I}\end{array}\right]$

Where for each $\mathrm{i}, \mathrm{j}=1, \ldots, \mathrm{I}$ That $\mathrm{i} \neq \mathrm{j}$, we'll have: $\mathrm{E}\left[\mathrm{e}_{\mathrm{t}}^{\mathrm{i}} \mathrm{e}_{\mathrm{t}}^{\mathrm{j}}\right]=0$

Considering equations (1) and (2), a FAVAR model is shown as follows:

$\left[\begin{array}{c}F_{t}^{1} \\ F_{t}^{2} \\ \cdots \\ F_{t}^{i} \\ Y_{t}\end{array}\right]=\varphi(L)\left[\begin{array}{c}F_{t-1}^{1} \\ F_{t-1}^{2} \\ \cdots \\ F_{t-1}^{i} \\ Y_{t-1}\end{array}\right]+v_{t}$

In where $\Phi(\mathrm{L})$ is a lagged polynomial with $\mathrm{d}$ degree that the number of VAR model lags is determined based on that. The difference between this model and a standard VAR model is the Presence of invisible factors F In this model. Bernanke et al. [3] presented two approaches to estimate the equations. The first approach is a two-step main component approach, which is non-parametric approach. The second one is the one-step accuracy Bayesian approach. These approaches differ in many aspects, and there is no clear reason for their superiority.

The two-step method is similar to the one used in Stoke and Watson's predictions. In this method, first step is estimating, the main component of $\mathrm{C}_{\mathrm{t}}$ by Using $\mathrm{K}+\mathrm{M}$ first main components of $\mathrm{X}_{\mathrm{t}}$. One of the useful features of this framework is the use of the maximization algorithm of expectation that allows to treat data disruptions systematically for example, Bernanke and Boyne (2003) estimated the factors in the case that $\mathrm{X}_{\mathrm{t}}$ includes both monthly and seasonal data.
$1,2,3, \ldots ., \mathrm{T}$ is also indicates the dimension of time. It should be noted that in the first phase, $\mathrm{Y}_{\mathrm{t}}$ views are not used. As Stoke and Watson (2002) showed when N is large and the number of main components used is at least the same as the number of factors, the main components recover information, consistently. Estimated factors $\widehat{F}_{t}$ are part of this information. In the second step, the FAVAR model, is Estimated with standard methods by replacing $\widehat{F}_{\mathrm{t}}$ by $\mathrm{F}_{\mathrm{t}}$.

\section{Developing a model for industrial units in Iran}

In almost all of the studies on the industrial sector in Iran, conventional methods such as single-equivalent least squares method, VAR model, auto regressive distributed lag (ARDL) model and vector error correction model (VECM) were used. It should be noted that the same problems as in study of monetary shocks effects in the form of standard VAR model (Or even error correction vector models), are also presents in these studies such as the inefficient use of available information and the selective selection of pattern variables. Therefore, examining the effect of monetary shocks on the country's industries requires the use of a more comprehensive and complete model.

The impact of monetary shocks on the country industries will affected six major variables, including the count of industrial units used, industrial employment, investment in the country's industries, as well as the number of issued establishment licenses, investment and employment in establishment licenses base on statement of applicants. In fact, these three concepts are the invisible factors in the industrial sector that make up the $F_{t}$ vector in the FAVAR model. In this regard, first the equation (3) for the industrial sector should be estimated and then using $\mathrm{F}_{\mathrm{t}}$ vector components. to Estimate the equation (4) model. To estimate the equation (3), we must first identify the vector components $\mathrm{X}_{\mathrm{t}}$. For this purpose, the data of the industrial sector, which represents the levels of activity of the industries, are examined and then efforts are made to make $X_{t}$ comprehensive and complete as far as possible, to solve the problem of in efficient use of information. According to the purpose of this article which is investigation of the effect of monetary shocks on the level of activities in the industrial sector, variables of vector $X_{t}$, should be chosen in a way that reflects that concept. Data used are annual data and are prepared from time-series data bank of central bank. time range of data is from 1357 to 1394 solar years. The index to indicate industry activity level is usually obtained from issued establishment licenses and operation licenses. Exploitation licenses and issued establishment licenses indicate the level of activity of the industrial sector in the desired year. In this regard, six main characteristics 
as vector blocks of $X_{t}$ has been used that these 6 indicators together indicate $\mathrm{X}_{\mathrm{t}}$ group. These indicators are named under the following headings:

Index of the count of exploit units (number of issued licenses): $\mathrm{X}_{\mathrm{t}}^{\mathrm{pcount}}$

Index of employment number of units in operation: $\mathrm{X}_{\mathrm{t}}^{\text {pemployment }}$

Index of Investment of exploited units: $\mathrm{X}_{\mathrm{t}}^{\text {Investment }}$
Index of the number of issued establishment licenses: $\mathrm{X}_{\mathrm{t}}^{\mathrm{j} \text { count }}$

Index of Employment in the license based on the statement of entrepreneurship applicants: $X_{t}^{\text {jemployment }}$ Index of investment based on the statement of entrepreneurship applicants: $\mathrm{X}_{\mathrm{t}}^{\mathrm{jInvestment}}$

Here equation (3) is rewritten as equation (4) as follows:

$$
\left[\begin{array}{c}
X_{t}^{\text {count }} \\
X_{t}^{\text {employment }} \\
X_{t}^{\text {Investment }}
\end{array}\right]=\left[\begin{array}{ccc}
\Lambda_{1}^{\text {count }} & 0 & 0 \\
0 & \Lambda_{2}^{\text {employment }} & 0 \\
0 & 0 & \Lambda_{3}^{\text {Investment }}
\end{array}\right] \times\left[\begin{array}{c}
F_{t}^{\text {count }} \\
F_{t}^{\text {employment }} \\
F_{t}^{\text {Investment }}
\end{array}\right]+\left[\begin{array}{c}
e_{t}^{\text {count }} \\
e_{t}^{\text {employment }} \\
e_{t}^{\text {Investment }}
\end{array}\right]
$$

The above equation is shown as open as follows:

$$
\left[\begin{array}{c}
X_{t}^{\text {pcount }} \\
X_{t}^{\text {jcount }} \\
X_{t}^{\text {Investment }} \\
X_{t}^{\text {jInvestment }} \\
X_{t}^{\text {pemployment }} \\
X_{t}^{\text {jemployment }}
\end{array}\right]=\left[\begin{array}{ccc}
\Lambda_{1}^{\text {count }} & 0 & 0 \\
0 & \Lambda_{2}^{\text {Investment }} & 0 \\
0 & 0 & \Lambda_{3}^{\text {employment }}
\end{array}\right] \times\left[\begin{array}{c}
F_{t}^{\text {count }} \\
F_{t}^{\text {Investment }} \\
F_{t}^{\text {employment }}
\end{array}\right]+\left[\begin{array}{c}
e_{t}^{\text {count }} \\
e_{t}^{\text {employment }} \\
e_{t}^{\text {Investment }}
\end{array}\right]
$$

Using estimation of equation (4), the factors or the same as $F_{t}^{i}$ are estimated. Based on what was stated in the previous section, the number of factors used will be 3 . To estimate the equation, one must first include identified the variables in the vector $\mathrm{Y}_{\mathrm{t}}$. According to the purpose of the article, which is to investigate the effect of monetary shocks on the country's industries, $Y_{t}$ should be Included the variables that represent monetary shocks. In several studies, it is common to use two, monetary base or liquidity variables, to specify and explain monetary shocks in VAR models. The difference between the two variables is that the monetary base is mainly determined by government policies (although in countries with independent monetary systems, it is the central bank that can directly determine the monetary base). While liquidity shows the effect of the increasing monetary coefficient and performance of banks and generally the credit system. What is considered important is the externality of these two variables in relation to the country's industries, while they are determined outside this sector and mainly by policymakers. Therefore, vector $\mathrm{Y}_{\mathrm{t}}$ will include two variables, liquidity and monetary base. It is necessary to explain that in order to solve the problem of unit root in the model estimation, liquidity growth rate and monetary base growth rate have been used. Therefore, equation (4) will be as follows:

$$
\left[\begin{array}{c}
F_{t}^{\text {count }} \\
F_{t}^{\text {Investment }} \\
F_{t}^{\text {employment }} \\
N_{t} \\
P_{t}
\end{array}\right]=\varphi(L)\left[\begin{array}{c}
F_{t-1}^{\text {count }} \\
F_{t-1}^{\text {Investment }} \\
F_{t-1}^{\text {employment }} \\
N_{t-1} \\
P_{t-1}
\end{array}\right]+v_{t}
$$

In where $\mathrm{N}_{t}$ and $\mathrm{P}_{\mathrm{t}}$ are as liquidity growth rates and monetary base growth rate, which one formed the vector $\mathrm{Y}_{\mathrm{t}}$.

\section{Model Estimation and Analysis}

\section{Model estimation}

In this study, following Bernanke [3] the two-step method to estimate the pattern of FAVAR model is Used. Due to the low number of data, in this study, the optimal number of interruptions is considered based on Schwartz's criterion, which the optimal interval for both equations (estimated monetary base shock and liquidity) are equal to one. One of the most important questions for estimating is to determine the number of factors that can cover the effects of monetary policy very well. It has already been stated that Bay and Angie (2002) and others have proposed different criteria for determining the number of factors. However, these criteria do not provide accurate answer to this question, and they cannot be used in the accuracy estimation method due to computational constraints. Therefore, in this study, based on the structure of vector $X_{t}$ And the variables introduced in this vector, three factors are selected.

Page | 12 
The present model is estimated through software EViews 9,5. According to the former statements, one of the methods used to estimate the model, is the twostage model. In this method, the factors or the $\mathrm{F}_{\mathrm{t}}^{\mathrm{i}}$ are estimated using factor analyzing method. Then in the next step, the generalized VAR model is estimated. All the characteristic roots of estimated equation, are within the unit circle that shows its stability. The normality test of the model residues shows that their normality assumptions are generally confirmed at the probability level of the first type of error of $5 \%$. In the Mentioned test, the hypothesis that; whether the residues from VAR model estimation? is a multivariate normal distribution or not? is analyzed and examined. In fact, this is a kind of model verification test, with the logic that if the considered model is correctly identified, the resulting residues must be completely random and follow a pattern of normal multivariate distribution. These tests can be done based on skewness, kurtosis or in general (simultaneous study of the skewness and kurtosis of variables). The important point is that it is not possible to perform the normality test directly using residues, thus before that it is necessary to multiply the residues matrix into a suitable matrix, in

Response to Cholesky One S.D. Innovations \pm 2 S.E.

Response of_FACROT1 to N100

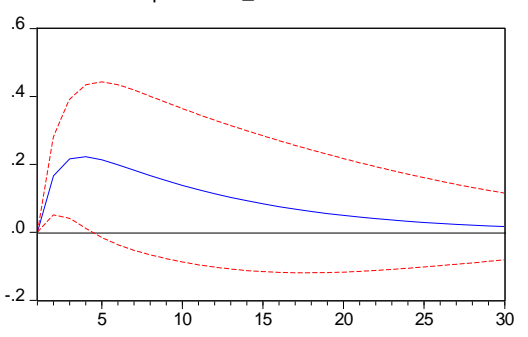

Response of _FACROT2 to N100

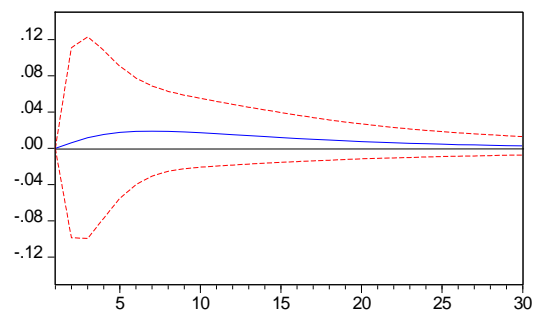

Response of_FACROT3 to N100

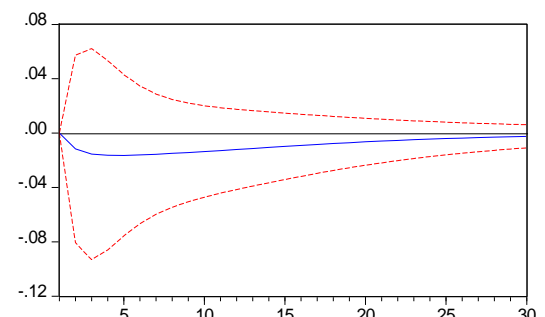

Figure 1. Analysis ${ }^{15}$ impulse response functions related to the effects of liquidity shock and monetary base shock

(Source: Research Findings) order to obtain balanced residues, and then perform the tests based on it. Accordingly, there are several normalization tests that use different coefficient matrices. Lutkepohl [8] suggests using an inverted lower triangular matrix of Cholesky to simplify residues. However, it should be noted that this method is sensitive to order the variables, and as this order changes, the results may change. In order to solve this problem, Urzua [9] proposed inverse square roots of the residual covariance matrix. Therefore, in this study the test for the normality of residues is based on the method of Urzua [9]. Based on test statistics and their P-Values and the comparison with the probability level of the first type error of $5 \%$, the residues in terms of skewness and kurtosis are similar to normal distribution and in genera based on Jarque-Bera statistics the assumption of normality of residues are confirmed. Considering the results of the normality test, as well as stability conditions of model, it can be accepted that the estimated model has appropriate characteristics and therefore can be the basis for analysis of reaction functions.

Response to Cholesky One S.D. Innovations \pm 2 S.E.

Response of _FACROT1 to P100

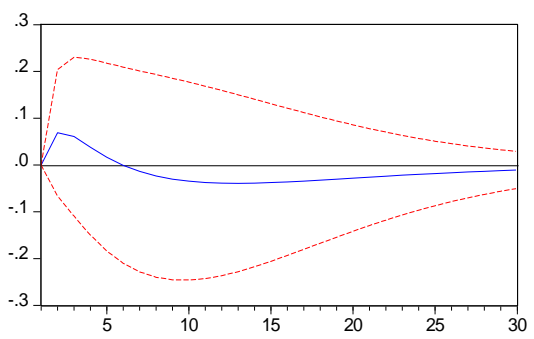

Response of_FACROT2 to P100

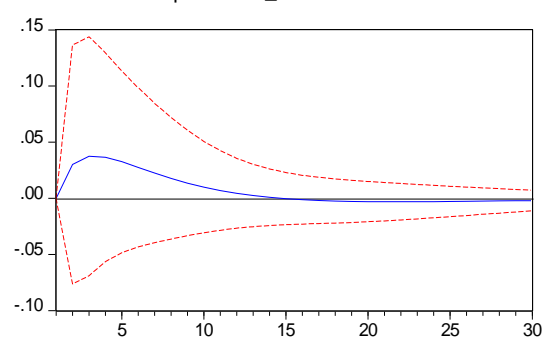

Response of _FACROT3 to P100

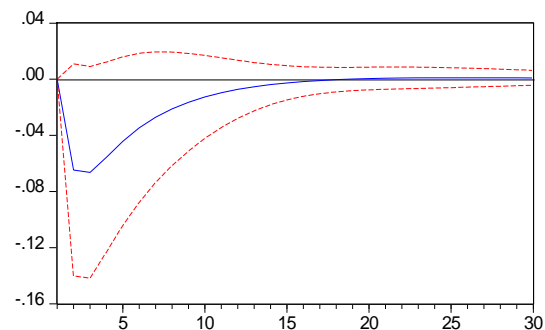




\section{Analysis of the Impulse Response Functions(IRF)}

At this stage, in order to analyze the effects of monetary shocks and liquidity on the level of activities of the country's industries, the impact impulse response functions of the estimation model are examined.An important issue in VAR analysis is the detection of shocks of each equation which is summarized from the residues form. In other words, if we are to interpret the residues of an equation as the shock on the dependent variable in that variable, first we must make sure that the shock is correctly defined. For this purpose, in experimental literature of VAR models various solutions have been proposed. For example, Sims [1] Use a recursive system in the shape of lower triangular matrix. which uses a Choleski decomposition system to synchronize summarized residual form. In this section the vertical axes in the diagrams show the reaction of the variables to the monetary and liquidity base shocks, and the horizontal axes represent the number of years that have taken for the shocks to effect on the variables. The mentioned time for charts studied have is 30 Years. Before analyzing the shocks, it needs to be addressed that factors are the same three factors that are estimated in the model in which factor 1 indicates the count of industrial units, factor 2 introduce the investment of industrial units and factor 3 represents the employment of industrial units. According to figure 1 , it is clear that the liquidity and monetary base shock has had a ripple-like effect on the level of industry activity

A monetary base shock as much as a deviation from the standard on the count of industries in the country, indicates that there is no reaction in the first period. from the first period to the second period, there is a positive and short-term reaction that reaches a maximum in the second period and then disappears with a downward trend over 5 periods. Regarding the monetary base shock on the investment of the country's industries, there is no reaction in the first period, but from the first period onwards, a positive and upward shock is observed, which reaches its maximum in the third period. then with one downward trend slows down over 14 periods. The effect of the monetary shock on the employment of the country's industries in the short term has a downward trend, but after several periods, this shock is dampened.

A liquidity shock as much as a deviation from the standard on the count of industries in the country, indicates that there is no reaction in the first period and from the first period onwards, it includes a positive reaction that reaches a maximum in the fourth period and then It goes through a downtrend over the course of more than 30 periods. Regarding the liquidity shock on the investment of the country's industries, at first there is no reaction in the first period, but from the first period onwards, a positive and upward shock is observed, which reaches its maximum in the seventh period and then disappears with a downward trend over more than 30 periods. The effect of liquidity shock on the employment of the country's industries, in the short run has a downward trend, but after several periods, this shock disappears.

\section{Conclusion and Recommendations}

The estimated immediate response functions show that a positive monetary shock (increase in the volume of money) has expansionary effects on the count of industries in the country and the investment of these industries in the Iran's economy. Immediate response functions show that the count of industries and their investment have a faster and more stable reaction in liquidity shock than monetary base shock. In other words, the effect of liquidity shock on the count of industries in the country decreases after 4 periods, but the effect of monetary base shock on the count of industries in the country decreases after 2 periods. Also, the effect of liquidity shock on investment in industrial industries after decrease 7 periods, but the impact of the monetary shock on the country's industry investment will decrease after 3 periods. The results in this section are consistent with the theoretical basis because the increase in volume of money in the short term affects macroeconomic variables such as the count of industries and industrial investment and shows a positive and increasing relationship. How macroeconomic growth affects economic activity by emphasizing real variables such as production and employment has been the subject of numerous discussions in macroeconomic literature. Many studies over the past three decades have focused on the shortterm effects of money growth on the real variables of the economy, including production and employment, emphasizing the difference between the predictable and unpredictable growth effects of money variables. Existing empirical evidence relates to the evaluation of the two nucleic and kinetic patterns. In the neoclassical model, the predicted changes in the money supply do not affect the actual variables, but the predicted growth of money affects the real variables in short-term. This approach, based on the hypothesis of rational expectations and contrary to Friedman, believes that non-systematic or irregular monetary policies affect real variables. Keynesian model believes that both components of money growth affect production and employment. Some Keynesians have also accepted the hypothesis of rational expectations, but believe that short-term economic policies are also effective.

Monetary shock on the employment of the country's industries has a negative impact. It is expected that based on conventional economic assumptions, whit increasing the amount of money, the general level

Page | 14 
of prices and inflation increase too; This is the inflation that causes employment growth in most economies, but in this study, employment is negatively influenced by monetary shock and the increase in money supply. This issue is important because the unemployment in the Iran's economy, regardless of monetary policy, is subject to other variables. The findings of other research conducted in Iran's economy also testify to the fact that the increase in the amount of money has the opposite effect on employment. According to the research findings, a positive monetary shock causes a negative wave in employment, due to the increase in the volume of money and the resulting inflation, the increase in wages and decrease in employment is occurred. The positive effects of money supply on production and consumption one as follows: first, production and consumption increase, and then by creating inflationary conditions by increasing wages and reducing employment production and consumptive will decrease.

\section{References}

1. Sims CA. Macroeconomics and reality. J Economet Soc. 1980; 48(1): 1-48.
2. Hsing Y. Responces of argentine output to shocks to monetary policy, fiscal policy and exchange rates: A VAR Model. Appl Economet Int Dev. 2004; 4(1): 1-16.

3. Bernanke BS, Boivin J, Eliasz P. Measuring the effects of monetary policy: A factor-augmented vector autoregressive (FAVAR) approach. Q J Econ. 2005; 120(1): 387-422.

4. Marzban H, Dehghan Z, Akbarian R, Farahani M. Assessing the effectiveness of monetary policy on the economy: FAVAR approach. I Quant Econ (Q J Econ Rev), 2016; 13(2): 71-92.

5. Bernanke B, Boivin J. Monetary policy in a data-rich environment. J Monetary Econ. 2003; 50(3): 525-546.

6. Bernanke B, Blinder A. The federal funds rate and the channels of monetary transmission. Natl Bureau Econ Res. 1990; 82(4): 901-958.

7. Boivin J, Kiely M, Mishkin FS. How has the monetaryv transmission mechanism evolved over time?. Handbook Monetary Econ. 2010; 3(1): 369-422.

8. Lutkepohl H. Introduction to Multiple Time Series Analysis. New York, Springer Verlag. 1991.

9. Urzua CM. Omnibus tests for multivariate normality based on a class of maximum entropy distributions. Adv Economet. 1997; 12(1): 341-358.

\section{SJAMAO}

Copyright: (C) 2021 The Author(s); This is an open-access article distributed under the terms of the Creative Commons Attribution License (http://creativecommons.org/licenses/by/4.0), which permits unrestricted use, distribution, and reproduction in any medium, provided the original work is properly cited.

Citation: Ranjbar Z, Kazem Etemad SM. Investigating the Effect of Monetary Shock on the Activity Level of Industrial Units in Iran Using the FAVAR Model. SJAMAO, 2021; 3(2): 8-15. 